\title{
RESOLVER EL PROBLEMA ABIERTO: TENIR LANAS A PARTIR DE PRODUCTOS COLORANTES NATURALES. UNA ACTIVIDAD INVESTIGATIVA PARA LA ENSEÑANZA SECUNDARIA OBLIGATORIA
}

\author{
MARTÍNEZ AZNAR, M. M. ${ }^{1}$ y OVEJERO MORCILLO, P. ${ }^{2}$ \\ ${ }^{1}$ Departamento de Dídáctica de las Ciencias Experimentales. Facultad de Educación. \\ Centro de Formación de Profesores. Universidad Complutense. Av. Filipinas, 3. 28003 Madrid. \\ 2 Instituto de Enseñanza Secundaria León Felipe. Av, de las Fuerzas Armadas, s/n. Getafe. \\ 28901 Madrid.
}

\begin{abstract}
SUMMARY
We present in this paper a class work for solving investigative problems, inserted into the theoretical constructivist context. We have chosen the topic «Dye wool with natural dyers», for its relevance in Organic Chemistry and also for its cultural and social interest, showing an actual perspective of Science.

On the other hand, we develop the class performance with emphasis in assessment.
\end{abstract}

\section{INTRODUCCIÓN}

El desarrollo del curriculo oficial de ciencias de la naturaleza para la ESO supone considerar diferentes contenidos (conceptos, procedimientos y actitudes) y un amplio rango de metodologías enmarcadas dentro del enfoque constructivista sobre el aprendizaje y el cambio conceptual (Porlán, 1995).

Dentro de esta perspectiva actual y puesto que la ciencia en sí puede entenderse como búsqueda de soluciones a los problemas que se nos plantean, consideramos que la resolución de problemas constituye y desempeña un papel fundamental en la enseñanza-aprendizaje de las ciencias, dirigido a producir un aprendizaje significativo y promover un cambio conceptual.

El planteamiento de situaciones problemáticas reales puede establecer además las conexiones entre los conceptos, los procedimientos y las actitudes que destacarian la funcionatidad de los conocimientos, poniendo de relieve la utilidad de lo que se aprende. Todo ello va encaminado a contemplar las interacciones entre las disciplinas científicas y el alumno dentro del contexto social y de desarrollo tecnológico en el que se desenvuelve.

Por otra parte, habria que destacar que este tipo de trabajos favorece la creatividad que, según Garret (1988), está asociada a la combinación entre sí de la originalidad y la utilidad. La relación entre creatividad y resolución de problemas ha sido defendida también por otros autores (Guilford,1976; Colkins et al., 1984).

Otra cuestion a considerar es que la resolución de problemas, básicamente, puede contemplarse: como una actividad de apoyo y consolidación para el aprendizaje de los contenidos conceptuales; y como referencia o punto de partida para la organización y desarrollo del currículo escolar. Con objeto de expandir esta última 
Figura 1

Propuesta de programación para el segundo ciclo de la ESO.

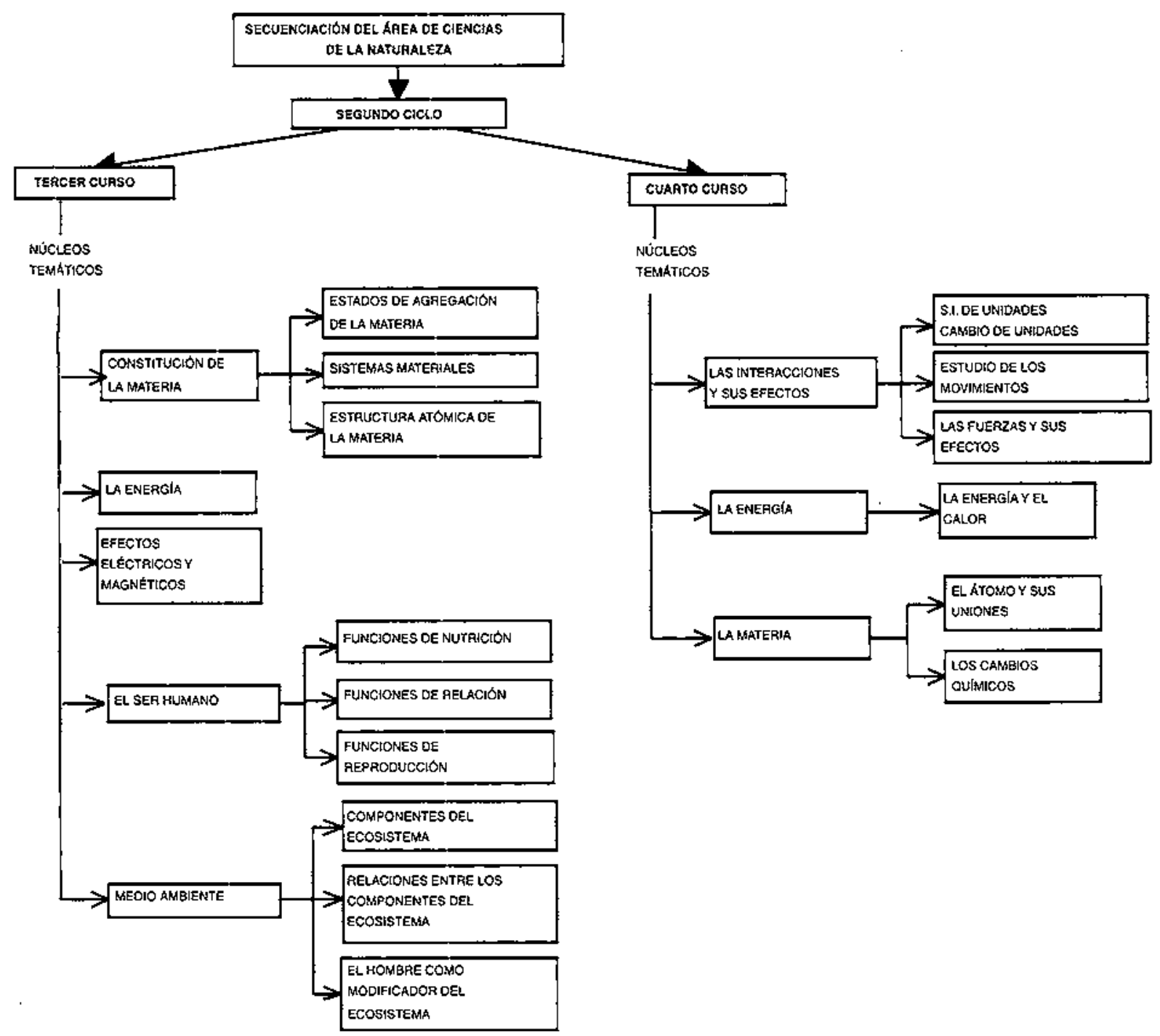

tendencia, que es la menos desarrollada, presentamos este trabajo que forma parte de una investigación más amplia para la enseñanza-aprendizaje del nứcleo «la materia», que creemos que puede ser altamente motivador y novedoso para los alumnos así como útil para que los profesores desarrollen sus enseñanzas e investigaciones de aula.

Dentro de las posibles metodologías existentes en la bibliografía, nosotras hemos realizado una inspirada en la propuesta de Gil y sus colaboradores (1990, 1985, 1983), para problemas abiertos de lápiz y papel, y en Ia del APU (1984), para problemas experimentales; además, hemos considerado para la metodología de trabajo en el aula Ias ideas de Osborne y Fryeberg (1991), por considerarlas acordes con los planteamientos indicados y con una perspectiva actual de concebir la ciencia y su enseñanza.

El trabajo que presentamos fue desarrollado, con alumnos de $3^{\circ}$ de BUP, de los IES León Felipe de Getafe e Ignacio Eliacuría de Alcorcón, durante el curso 1991-92, y en estos momentos puede adaptarse a alumnos de $3^{\circ}$ de ESO, dado que los contenidos que se abordan se pueden enmarcar en las nuevas programaciones que para esta etapa se están desarrollando en los centros de secundaria.

El tema elegido para el trabajo con los alumnos ha sido «los tintes y colorantes naturales». Su elección se debe a que: 
a) partiendo de este tema considerado como centro de interes, se podrán desarrollar diversos aspectos del bloque temático "constitución de Ia materia», que forman parte de la programación del 3r. curso de la ESO tal como aparcce en el esquema de la figura 1;

b) refleja cl interés cultural y económico que los colorantes textiles han venido teniendo a lo largo de la historia del hombre; $y$

c) constata cómo la necesidad que dio lugar a la fabricación de colorantes sintéticos promovió tanto el desarroIlo de Ia química orgánica como la teoría química. Al mismo tiempo condujo a la obtención de constantes y nuevos descubrimientos que llevaron a progresos científicos y sociales.

\section{OBJETIVOS}

En el trabajo se planteó:

- Elaborar y diseñar materiales que permitan al alumno desarrollar y aplicar estrategias personales en la resolución de problemas, utilizando las pautas de acción propias de la investigación científica de la realidad.

- Proporcionar a los profesionales de la enseñanza un ejemplo de pautas metodológicas a seguir sobre el enfoque y resolución de problemas abiertos en la enseñanzaaprendizaje de las ciencias, así como un ejemplo de problema para favorecer el desarrollo de la enseñanza y la investigación en el aula.

- Discñar materiales para la evaluación de las actividades elaboradas.

\section{METODOLOGÍA}

Este trabajo se refiere a actividades de tipo investigativo, sugeridas en las «pequeñas investigaciones» 0 «actividades de investigación libre» de Ias orientaciones didácticas oficiales, y pretenden que el alumno comprenda la naturaleza de los problemas relacionados con el conocimiento científico y las estrategias y técnicas involucradas en su resolución.

En esta metodología se plantea la necesidad de que tanto el profesor como el alumno adopten un papel coherente con el enfoque constructivista. Así, tendremos que encaminar la actividad del aula a:

a) conseguir que los alumnos pongan en cuestión sus ideas;

b) contrasten estas ideas con sus compañeros;

c) emitan hipótesis con los resultados aportados por la experimentación o el profesor;

d) apliquen las nuevas ideas a otras situaciones.
Ello supone que el profesor debe dejar de ser un mero transmisor de conocimientos ya elaborados para asumir otros roles en consonancia con el nuevo enfoque metodológico. Entre éstos cabe destacar al profesor como motivador, guía e innovador-investigador.

Por otra parte, «el papel del alumno consistirá en construir sus aprendizajes realizando las actividades propuestas, dando respuesta a problemas planteados, aprendiendo a trabajar de forma autónoma, siendo capaz de tomar iniciativas y de acoplarse al trabajo de equipo" (Diseño Curricular Base [Cajas Rojas], 1992, p. I16).

\section{Entrevistas previas a los alumnos}

Con objeto de conocer y analizar las etapas que emplea el alumno en la resolución de problemas, así como las dificultades que se generan en dicho proceso, elaboramos y grabamos entrevistas semidirigidas donde los alumnos expusieron sus ideas.

Las cuestiones fueron del tipo: ¿Qué es un problema? ¿Qué tipos de problemas conoces? ¿Qué entiendes por problema abierto y problema cerrado? ¿Qué típos de problemas te plantea el profesor en el aula? ¿Qué etapas utilizas para resolver un problema? ¿Qué etapa/s te plantea/n mayor dificultad? ¿Cuáles crees que son las causas de estas dificultades? ¿Sigues siempre el mismo método en la resolución de problemas? ¿Analizas los resultados obtenidos? ¿Cómo resuelves los problemas, individualmente o en grupo? ¿Crees que los problemas planteados en el aula tienen aplicación a la vida real?

Las respuestas que por su amplitud, aquí y ahora, no se desarrollan merecen alguna consideración por su implicación en el desarrollo de materiales y sesiones de trabajo.

Los alumnos identifican problema con obstáculo y en general, influenciados por metodologías tradicionales, contemplan los problemas realizados en el aula como cerrados.

En relación con las etapas utilizadas para la resolución, se observa una gran uniformidad en las contestaciones, que podemos resumir en: lectura del enunciado, recogida de datos, búsqueda de fórmulas y resolución. Estas etapas, parece lógico pensar que son las enseñadas por los profesores y que aparecen reseñadas en la bibliografía como propias de modelos tradicionales de resolución de problemas (Gisbert, 1985).

La dificultad más destacada, con gran diferencia de las demás, es la búsqueda y uso de algoritmos para la resolución.

En relación con eł método seguido para resolver problemas, cabe indicar como respuesta mayoritaria, la tendencia a imitar las pautas seguidas por el profesor en la resolución de problemas en la pizarra; en general, los alumnos realizan estas tareas de forma individual y en $\$ u$ casa. 
Por último, mencionaremos que, desde el punto de vista de los alumnos, los problemas que se plantean en el aula no tienen aplicación a la vida real.

\section{Material diseñado para el alumno}

En primer lugar se llevó a cabo la elaboración de un manual que recoge toda la información imprescindible para que el alumno pueda resolver la situación probiemática propuesta.

La revisión de la literatura nos refleja que el tema propuesto se aborda desde perspectivas diferentes: una de carácter científico y técnico muy especializada (Klages, 1968) y que excede el nivel educativo de los alumnos; y otras desde el punto de vista divulgativo, como meros «recetarios» (Let Van de Vrande, 1988; Ballesteros, J.R., 1986), donde los aspectos químicos y el rigor científico prácticamente han sido evitados. Por otra parte, tampoco se dispone de textos escolares que abarquen este tema con la extensión y características requeridas para el caso. Además, el enfoque metodológico de los problemas de investigación abierta precisa contemplar aspectos y conocimientos colaterales, aunque no expresamente relacionados con el tema propuesto.

El manual elaborado por nosotros, bajo el título «Teñido de la ları con productos colorantes naturales" se presenta en diferentes colores de acuerdo con las posibles coloraciones obtenidas a partir de los productos colorantes naturales a emplear. Consideramos que, aparte de motivadora, esta presentación resulta práctica a la hora de realizar la consulta y permite diferenciar Jos distintos aspeckos de los contenidos.

A continuación exponemos la relación de bloques y contenidos en los que puede desglosarse dicho manual:

1. Aspectos relevantes sobre la química del teñido de la Iana.

1.1. Aspectos históricos del teñido.

1.2. Química del teñido.

1.3. Fibras.

1.4. Productos naturales tintóreos.

1.5. Mordientes.

1.6. Productos químicos utilizados en el teñido de Ia lana.

2. Aspectos prácticos para su uso en el laboratorio. 2.1. Material de Iaboratorio.

2.2. Normas de seguridad.

3. Conceptos básicos físico-químicos.

3.1. Teorías físico-químicas del color.

3.2. Sistemas materíales. Métodos de separación de los componentes de una mezcla.

3.3. Características de las reacciones químicas: Aspectos fenomenológicos sobre ácidos y bases.

Los productos colorantes naturates empleados por los alumnos fueron: agallas, cebolla, cochinilla, cúrcuma y saúco. A modo de ejemplo, en el anexo I, se adjunta la información que aparece en dicho manual en los apartados 1.3 y 1.4 , correspondiente a la cochinilla y a la cebolla, así como la clasificación de las lanas españolas.

Asimismo, elaboramos un «muestrario» que ejemplificaba las coloraciones que podrían obtener los alumnos.

\section{Agrupamientos}

En la perspectiva constructivista del aprendizaje de las ciencias, se hace énfasis en la importancia de la interpretación individual de los procesos de construcción del conocimiento. Pero también hay que considerar que el trabajo colaborativo entre los alumnos proporciona interacciones que les dan la oportunidad de negociar los significados y las ideas a aprender (Wheatley, 1991).

Teniendo en cuenta estas consideraciones, una de las primeras tareas del profesor consiste en determinar uel método de trabajo". En éste, uno de los aspectos a determinar es la organización de los alumnos en forma grupal o individual. Estas distribuciones se pueden realizar atendiendo a diferentes criterios como, la homogeneidad de los alumnos (intereses comunes, nivel académico semejante), heterogeneidad (agrupando alumnos con diferente o distinto nivel de desarrollo de destrezas o conocimientos) o bien dejándoles libertad para que ellos se agrupen. En nuestro caso concreto nos inclinamos por una organización por parejas y libre, en la línea del aprendizaje cooperativo cuyos beneficios se han puesto de manifiesto en la literatura (Watson, 1991).

\section{Temporalización del trabajo}

También tenemos que considerar que el profesor debe distribuir la actividad en un número determinado de sesiones, las cuales pueden ser ampliadas según las necesidades que vayan surgiendo a to largo de la misma. En el trabajo propuesto, las actividades se llevaron a cabo en cuatro sesiones de dos horas cada una.

Como los alumnos de $3^{\circ}$ de BUP, con los que se trabajó, ya habían tratado los conocimientos básicos sobre «la materia" en cursos previos, los distintos aspectos teóri$\cos$ se fueron tratando según las necesidades de los alumnos (durante el desarrollo del trabajo experimental en cada grupo o en las puestas en común para el gran grupo).

Además se dispuso de seis horas al finalizar las sesiones para desarrollar, ampliar y profundizar los aspectos teóricos.

Al final đe cada sesión se empleó un pequeño espacio de tiempo a la puesta en común, promoviéndose debates que aportaron interrogantes y sus soluciones. También los primeros diez minutos se dedicaron a retomar las ideas generadas en la sesión anterior con fines metacognitivos y para ir permitiendo que los alumnos se distribuyeran el tiempo disponible. 
A continuación se analizan las sesiones realizadas:

\section{Primera sesión}

Se inició con la presentación del probłema abierto cuyo enunciado fue «Teñir lanas a partir de productos colorantes naturales».

Después se mostró el material didáctico del que podrían disponer en la biblioteca del laboratorio: manual y muestratio realizados por los profesores, libros de consulta, productos naturales tintóreos (agallas, cáscara de ceboIla, cochinilla, cúrcuma y saúco), material de laboratorio, etc. Seguidamente se presentó la metodología que deberían seguir los alumnos y que aparece en el cuadro I.

\section{Cuadro I}

Propuesta metodológica para la resolución del problema.

Etapas para la resolución de problemas:

1) Delimita el problema según tu deseo y posiblidades.

2) Plantea hipótesis sobre la utilización de los productos tintoreos y químicos para obtener la coloración deseada.

3) Elabora un plan de trabajo y un diseño de teñido.

4) Realiza el plan.

5) Analiza los resultados desde la hipótesis de trabajo.

6) Presenta nucvas propuestas, hipótesis y planes alternativos de trabajo.
Se recomendó a los aíumnos ia elaboración de una hoja resumen para que plasmasen las anotaciones sobre los pasos que fueran siguiendo para resolver el problema. Podemos destacar que de forma generalizada las propuestas de trabajo realizadas por nuestros alumnos coincidían en incluir:

- Elección del color y su justificación.

- Elección del producto natural tintóreo que les puede proporcionar el color deseado.

- Constatación de la necesidad del mordiente.

En el cuadro II incluimos dos ejemplos de estas hojas resumen.

En esta sesión, algunos alumnos comienzan su parte experimental preparando disoluciones para el mordentado y obteniendo el colorante.

Además, a lo largo de la puesta en común surgieron nuevas dudas que podemos resumir en las siguientes preguntas:

¿Cómo puedo extraer el colorante del producto natural tintóreo? ¿Necesitaría triturar la cochinilla? El mordentado y el baño de teñido, ¿se realiza a la vez? ¿Podré mordentar en frío? ¿Cuánto tiempo voy a tener la lana en el mordentado a ebullición? ¿Cómo puedo comprobar Las tonalidades a medida que se desarrolla el proceso, para poder después elegir la que más me guste? ¿Cómo voy a identificar las diferentes lanas con las que experimente para poder elegir al final el tono que más me

Figura 2

Métodos de teñido diseñados por los alumnos en la segunda sesión.

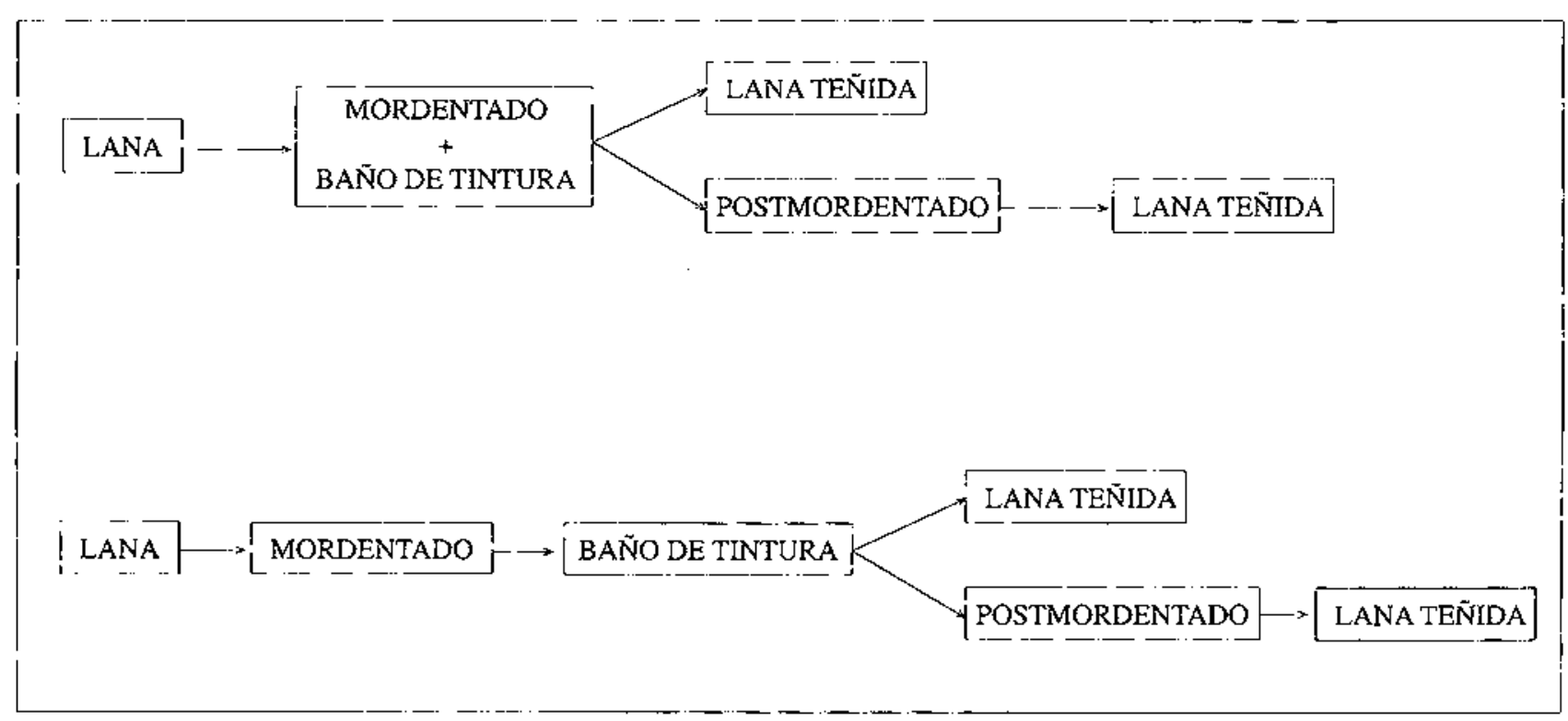


Cuadro II

Ejemplos de hojas resumen realizadas por dos alumnos.

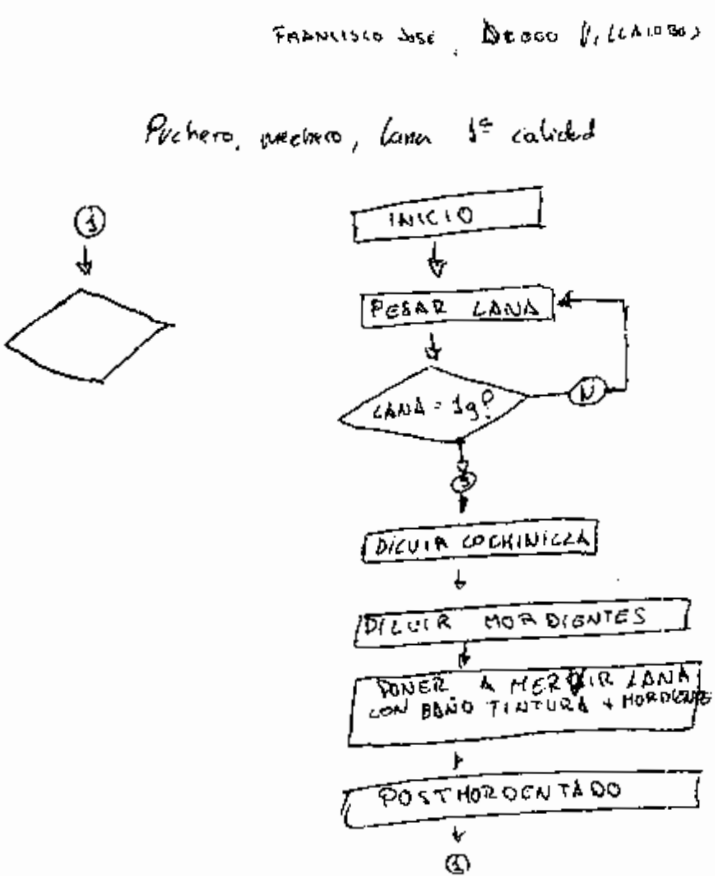

guste? ¿Necesito revelado? ¿Quć concentración tengo que utilizar?

Las posibles respuestas a estos interrogantes se deben ir resolviendo durante el propio debate, bajo la guía del profesor que controla la rigurosidad científica y aporta algunas ideas siempre que sea imprescindibles.

En esta sesión se cubrieron los siguientes aspectos:

- Búsqueda, clasificación e interpretación de la información disponible.

- Toma de decisiones.

- Diseño del plan de trabajo.

- Especificaciones sobre el método a utilizar.

- Emisión de las hipótesis de trabajo.

- Intercambio de ideas o colaboración entre grupos de alumnos.

$$
\text { Ff N } N^{\circ}+3^{\circ} D \text { Gsupot. 22-4.92 }
$$

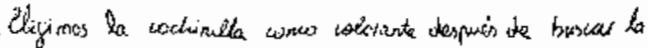

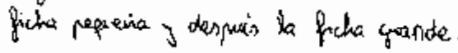

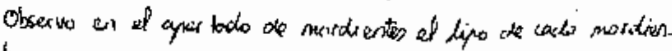

te que vamas a sililizer.

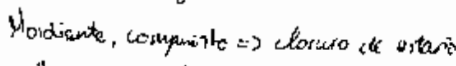

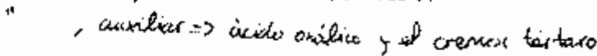

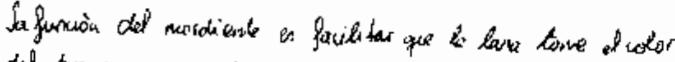
det tericdo, que as at ron.

in lavio,

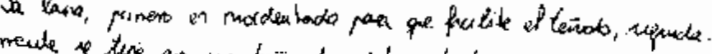

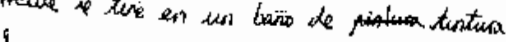

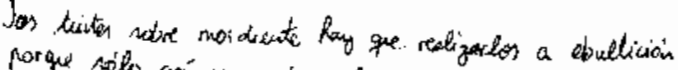

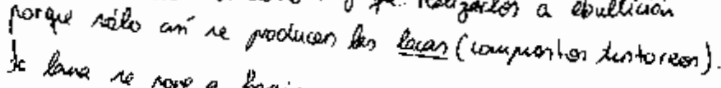

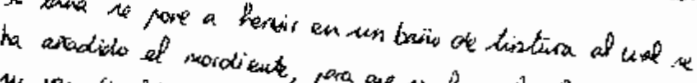

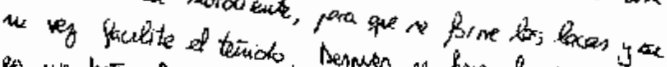

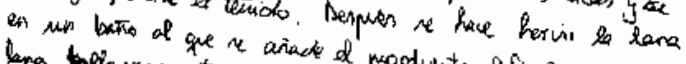

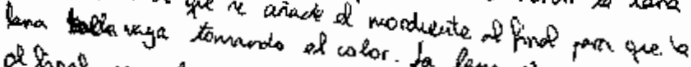

de finat re ackara en calienter. Ia lana as mordide.

te wbre(II).

bs cantidedis elegiclas de mordiente son:

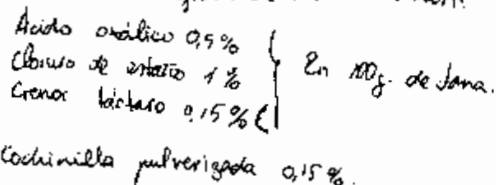

\section{Segunda sesión}

En la puesta en común inicial, los estudiantes emitieron las siguientes cuestiones:

¿Cómo son los sistemas que estamos utilizando, homogéneos o heterogéneos? ¿Cómo se debe expresar la concentración? ¿Cómo influirá la concentración tanto del mordiente como del producto colorante en el teñido de la lana? ¿Influirá el tiempo de permanencia de la lana en el mordentado y en el baño de tintura para la tonalidad del color? ¿Cómo prepararemos la lana? ¿Necesita algún tratamiento previo antes de mordentar?

En esta sesión se inició plenamente el trabajo experimental de todos los grupos; así, por ejemplo, se prepararon las disoluciones de los mordientes, se extrajo el colorante del producto natural tintóreo y se procedió al 
teñido de la lana según el método diseñado por los alumnos. A modo de ejemplo presentamos en la figura 2 alguno de los métodos de teñido diseñados por los alumnos. Hay que indicar que prácticamente cada grupo generó su diseño particular. Este đato corrobora el hecho de que este tipo de actividades problemáticas potencian la creatividad de los alumnos.

Al finalizar la sesión, en la puesta en común surgieron las siguientes preguntas:

Algunos mordientes no son totalmente solubles, ¿cómo aumentamos su solubilidad? ¿Cómo afecta la temperatura a la estabilidad de las disoluciones? En el caso particular de emplear como producto natural tintóreo la cúrcuma, la filltración a presión atmosférica y con filtro liso es muy lenta, ¿cómo puede ser más rápida? Al mordentar con dicromato de potasio y posteriormente teñir, no sc obtiene el color descado, ¿se habrá oxidado?, ¿le habrá afectado la luz? ¿Qué tenemos que hacer para que el color obtenido sea más intenso y ampliar la gama de colores?

Podemos considerar que se siguieron cubriendo los mismos aspectos que en la primera sesión y además:

- Especificaciones sobre las variables que intervienen. - Originalidad y creatividad en las propuestas realizadas.

- Presentación de las posibles soluciones del problema al resto del grupo.

- Planteamiento de nuevos problemas surgidos a partir del trabajo realizado.

\section{Tercera sesión}

Los alumnos continuaron con su trabajo experimental según la planificación elaborada por elios.

Podemos destacar que, en esta fase, los grupos de alumnos comenzaron a ser conscientes de la influencia de las distintas variables como el tiempo, la temperatura, el $\mathrm{pH}$, etc. y de la necesidad de su control en el proceso de teñido.

En este caso, como en sesiones anteriores, en la puesta en común final se cuestionaron ideas y surgieron nuevos interrogantes. También se dieron soluciones a preguntas planteadas en sesiones anteriores y que se habrían contrastado experimentalmente.

Por ejemplo:

- Cuanto más tiempo permanece la lana en el baño de tintura, más intenso es el color.

- A mayor concentración del mordiente, mayor es la fijación del color, ya que se obtienen colores más intensos.

Del desarrollo de toda la sesión podemos resumir que en ésta se produjo la reestructuración o replanteamiento del diseño, aportándose innovaciones e introduciendo modificaciones. El proceso posibilitó también aprender a comparar, discutir y evaluar los resultados de los otros grupos, reconociendo sus logros y deficiencias.

\section{Cuarta sesión}

En la puesta en común inicial volvieron a surgir de nuevo preguntas, que en nuestro caso concreto fueron principalmente de carácter conceptual como:

¿Qué es el color? ¿Cuál es la fórmula del pigmento? ¿Son nuestros colorantes indicadores? Etcétera.

En esta sesión se concluyó la parte experimental.

En nuestro caso particular y relacionado con alguna de las cuestiones propuestas, algún grupo de alumnos procedió a comprobar el posible carácter indicador de sus colorantes. Fruto de la familiarización adquirida con el tema y con la manipulación y uso de los materiales, algunos estudiantes propusieron diseffos alternativos a los realizados inicialmente.

Concluidas las sesiones, el profesor-investigador propuso la elaboración de un dossier donde se especificasen las etapas, diseños... y desarrollo del trabajo, todo ello realizado con el rigor, claridad y precisión requeridos en los informes científicos.

Es preciso indicar que todas las sesiones fueron grabadas en vídeo y que las conversaciones y discursos de los grupos fueron grabadas en audio.

\section{Seminarios de reflexión y recapitulación}

Durante la realización práctica đel trabajo en el laboratorio, los profesores percibieron las dificultades que terian los alumnos para interpretar y operativizar aspectos conocidos anteriormente y aquéilos que iban surgiendo en relación con el tema planteado.

Por ejemplo, se puso de manifiesto la falta de claridad en los conceptos de sistemas homogéneos y heterogéneos, lo que supuso en un principio la identificación de unos con otros, lo cual les llevó a cometer errores en la cuantificación de la cantidad de materia cotorante empleada. De la misma forma se aplicaron técnicas de preparación de disoluciones a mezclas heterogéneas insolubles. En relación con el concepto de solubilidad, conocido por los alumnos, se comprobó que, aunque sabían los aspectos que afectan al mismo, no los tenían en cuenta en la práctica hasta que les surgió la necesidad, por ejemplo, de extraer los colorantes del producto natural tintóreo de una forma práctica y efectiva. Así, la trituración, la elevación de la temperatura, etc., variables que influyen en el proceso, surgen después de discusiones entre los alumnos y de la interacción con el profesor.

Por todo ello, además de tratarse los aspectos conceptuales y sobre procedimientos durante las sesiones, como ya se ha indicado, se sugiere la necesidad de llevar a cabo algunos seminarios posteriores en los que se reestructuren y reorganicen tanto las ideas que surgieron durante el 
trabajo como otras colaterales de interés, no consideradas o abordadas de forma inadecuada por los alumnos y que se contemplan en la programación del núcleo iemático. Por otra parte, la cinta de vídeo grabada se puede proyectar a los alumnos con fines metacognitivos.

No obstante, se debe considerar que, dependiendo de los grupos de alumnos, estos seminarios tendrán dinámicas distintas.

\section{EVALUACIÓN DE LOS ALUMNOS EN EL PROBLEMA PLANTEADO}

Vamos a considerar esta evaluación con relación a:

\section{1) Contenidos conceptuales}

A. Como criterios de evaluación se han considerado:

- Clasificar sistemas materiales.

- Distinguir sistema homogéneo de heterogéneo.

- Distinguir sustancias puras y algunas mezclas importantes para su uso en el laboratorio, la industria o la vida diaria.

- Definir la solubilidad de una sustancia.

- Reconocer Ios componentes de una disolución y los tipos de disoluciones.

- Distinguir los conceptos de disolución diluida, concentrada y saturada.

- Conocer las formas más sencillas de medida de la concentración de una disolución.

- Separar mezclas teóricas construyendo mapas conceptuales conocidas las propiedades características.

- Saber identificar ácidos y bases.

- Conocer algunos aspectos físicoquímicos sobre el color.

B. Las técnicas utilizadas para llevar a cabo esta evaluación son:

\section{B.1. Cuestionario de ideas alternativas}

Previo al inicio de las sesiones, los profesores diagnosticaron las ideas alternativas de los estudiantes a través de un cuestionario. Para ello, se han elegido pruebas ya utilizadas en la bibliografía para analizar los contenidos conceptuales implicados en el problema investigativo (Llorens, 1991; Pozo et a1., 1991; Osborne y Fryeberg, 1991; Driver et al., 1989; Hierrezuelo y Montero, 1988; CLIS, 1986). (Anexo I1).

También la observación directa realizada por el profesor, la visualización y análisis de las grabaciones en vídeo y la puesta en común son muy apropiadas para detectar y conocer estas ideas.

\section{B.2. Cuestionarios finales}

Al finalizar las sesiones se distribuyó a los alumnos unos cuestionarios (Anexo III) con las siguientes finalidades:

Cuestionario I. Encaminado a explorar el diseño escogido y la toma de decisiones para la resolución del proble ma abierto.

Cuestionario II. Abarca tres aspectos: A, referido a los contenidos específicos del problema a tratar, «tintes y colorantes naturales»; $\mathrm{B}$, sobre aspectos curriculares implicados en el problema planteado; y $\mathrm{C}$, acerca de aspectos específicos del producto natural tintóreo elegido por cada grupo.

En relación con el cuestionario I, podemos destacar que el $80 \%$ de los alumnos no justifica en sí el điseño escogido, limitándose a mencionar el color con el que desean teñir. El 99\% ha ido reelaborando las decisiones inicialmente tomadas en funcion de Ios resultados parciales conseguidos y, de éstos, el $85 \%$ lo hace variando las concentraciones del pigmento y los tiempos de ebullición empleados.

Sobre el cuestionario IIA, todos los alumnos definen con precisión qué es un colorante, sin embargo el $70 \%$ sólo se refiere al colorante que ha utilizado en su experiencia. También la totalidad de los sujetos define mordiente correctamente, mencionádose en un $86 \%$ varios ejemplos. Esto quizás se deba a la necesidad de tener que buscar tonalidades distintas de las obtenidas inicialmente o de las presentadas en el muestrario o en el manual.

En el cuestionario IIB, se detectó que un $84 \%$ de los alumnos eran capaces de entender, identificar y usar correctamente conceptos básicos sobre mezclas, disoluciones, solubilidad, ácidos y $\mathrm{pH}$, frente al $45 \%$, que contestaron adecuadamente a las preguntas $6,7,8$ y 9 relativas a estos contenidos del cuestionario de ideas previas. Sin embargo, las ideas sobre el color no han sido adquiridas de forma precisa, así lo demuestran el $14 \%-15 \%$ de respuestas correctas a las dos últimas preguntas del cuestionario.

Por último, el $89 \%$ respondió adecuadamente al cuestionario IIC como cabría esperar, al ser específico del pigmento con el que los alumnos trabajaron.

\section{2) Contenidos de procedimientos}

A. Los criterios para la evaluación de los procedimientos fueron:

- Calcular la concentración de una disolución en $\mathrm{g} / \mathrm{L}$, porcentaje en peso o volumen, y $M$.

- Preparar una disolución, dada su composición en $g / L$, porcentaje en peso o volumen. 
- Conocer las técnicas más sencillas para separar los distintos componentes de las mezclas.

- Realizar montajes de laboratorio, cumpliendo las normas de seguridad y reconociendo el nombre del material.

- Analizar el planteamiento del diseño para la resolución de la situación problemática.

- Considerar la adecuación de las hipótesis planteadas, ta interpretación de los resultados, la comunicación de Ias conclusiones y la exposición de las mismas.

B. Las técnicas empieadas para constatar los resultados obtenidos fueron plantillas para la observación directa de la actividad del alumno y la discusión entre grupos (Anexo IV), las hojas resumen, los dossieres y las grabaciones en vídeo de las sesiones.

Sobre Ios resultados extraídos podemos considerar que los alumnos progresan de forma muy destacable respecto a la formulación de hipótesis, que en un principio les planteaba dificultades. En el anexo $\mathrm{V}$ se incluyen algunos de los procesos experimentales diseñados por distintos grupos de alumnos. También el $90 \%$ era capaz de desarrollar un proceso experimental acorde con sus objetivos e hipótesis. No obstante, tan sólo el $49 \%$ era capaz de identificar las variables que pueden influir en eI desarrollo, indicando su naturaleza, su número, así como ta relación y el control de las mismas.

\section{3) Contenidos sobre actitudes}

A. Los criterios de evaluación actitudinal utilizados fueron:

- Conocer y cumplir las normas de seguridad en el laboratorio y el cuidado del material.

- Tener en cuenta la opinión de los compañeros durante la realización de las actividades y colaborar con el grupo.

- Tomar postura, previa información.

- Argumentar las opiniones.

- Apreciar la importancia de los colorantes en nuestro mundo actual.

- Valorar el orden, claridad y limpieza en Ios dossieres elaborados.

B. Técnicas empleadas. La objetividad de la evaluación de aspectos afectivos y motivacionales siempre plantea grandes dudas a la hora de ser considerados. En metodologías como la que se presenta aquí, estas características resultan especialmente interesantes, puesto que el punto de partida del problema abierto se fundamenta en el interés que pueda suscitar en el alumno y, por otra parte, manifiesta claramente actitudes propias del trabajo cien- tffico. La observación directa del trabajo en y entre grupos, las ideas aportadas en la puesta en común y los vídeos grabados son puntos claves para efectuar esta evaluactón.

En este caso concreto, se diseñó una plantilla para expresar el grado en que se manifiesta la actitud considerada o el nivel de desempeño de la misma y se facilitó un cuestionario dirigido a determinar la valoración de la actividad realizada por parte de los estudiantes (Anexo VI). En relación con las actitudes científicas y en un porcentaje superior al $60 \%$ consideran bastante y mucho los aspectos relacionados con las opiniones de los compañeros, con su colaboración en el grupo, cumplimiento de normas y curiosidad. Consideran suficiente en más de un $60 \%$, aspectos relativos a toma de postura, cambio de opinión y argumentación de opiniones. Como dato peculiar solamente un $2 \%$ ha tenido en cuenta muy poco la opinión de los compañeros durante la actividad.

Para finalizar este apartado debemos indicar que el dossier confeccionado por cada grupo de trabajo, que ponía el colofón a sus actividades, fue tenido en cuenta para matizar y completar la evaluación. Presentamos algunas aportaciones cxpresadas en los dossieres:

«La expertencia ha sido muy positiva por el hecho de tenernos que enfrentar a unos problemas que nosotros mismos teníamos que resolver, sacando nuestras conclusiones de ese problema y de su resolución. Nos ha permitido familiarizarnos con los materiales del laboratorio de química, lo que nos será de gran ayuda para el futuro. El hecho de trabajar en equipo permite la ayuda mutua y de esta manera obtener unos resultados más favorables. Otro aspecto que también nos ha gustado ha sido la exposición al final de cada sesión de las conclusiones de cada grupo que sirven de mucho provecho a la hora de resolver tus propias dudas.»

«Ha estado bien porque eres tú mismo quien tiene que averiguarlo todo y pensar cómo se puede mejorar, relacionando los conocimientos que ya tienes y ampliándolos.»

\section{CONSIDERACIONES FINALES}

En síntesis, podemos resaltar que la resolución de problemas abiertos de tipo investigativo puede constifuir un tipo de actividad altamente significativa para el aprendizaje de los alumnos, que les permitirá comprender contenidos así como la utilización de las metodologías propias de la ciencia actual.

En relación con el profesor, adquirió un papel de investigador, enmarcado en la investigación-acción en que no se distingue entre la práctica que se investiga y el proceso de investigación de esa práctica; participa en el proceso de estudio y mejora de su propia experiencia en colaboración con otros profesores. 
Esta metodología permitió desarrollar una amplia variedad de instrumentos para la evaluación formativa de los alumnos que puede servir de ayuda para el día a día de la práctica docente.

\section{EPÍLOGO}

Esta actividad fue evaluada externamente por un equipo psicosociológico a través de la técnica de «entrevista en profundidad, semidirectivas, reflexiva y dinámica [...] para tener mayor acercamiento a los estudiantes". Dei informe de esta evaluación podemos destacar que los alumnos involucrados la consideraron como una experiencia muy positiva y útil para su aprendizaje, que les permitió convertirse en «individuos con capacidad de pensamiento y acción”, y que les llevó a motivarse y a

\section{REFRENCIAS BIBLIOGRÁFICAS}

APU (Assessment of Performance Unit) (1984). Science Reports forteachers: 2. Inglaterra: Association for Science Education, Herts.

BALLESTEROS, J.R. (1986). Las plantas tintoreas. Madrid: Ediciones Penthalon, S.A.

CLIS (1986). Aspects of secondary student's understanding of elementary ideas in chemistry. Full report. Leeds: HMSO.

DRIVER, R., GUESNE, E. y TIBERGHIEN, A. (1989). Ideas cientificas en la infancia y la adolescencia. Madrid: MorataMEC.

DISEÑOCURRICULAR BASE. Cajas Rojas. (1992). Secundaria obligatoria. Ciencias de la naturaleza. Madrid: MEC.

GARRET, R.M. (1988). Resolución de problemas y creatividad. Implicaciones para el currículo de ciencias. Enseñanza de las Ciencies, 6(3), pp. 224-230.

GIL, D. y CARRASCOSA, J. (I990). What to do about science misconceptions? Science Education, 74(5), pp. 531-540.

GIL, D. y CARRASCOSA, J. (1985). Science leaming as a conceptual and methodological change. European .Journal of Science Education, 7(3), pp. 231-236.

GIL, D. y MARTÍNEZ-TORREGROSA, J. (1983). A model for problem solving in accordance with scientific methodology. European Journal of Science Education, 5(4), pp. 447-455.

GISBERT, M. (1985). Método de resolución de problemas de física y química. Enseñanza de las Ciencias, 3, pp. 213-215.

GUILFORD, J. (1976). Estructura de referencia para el comportamiento creativo en elarte. Implicaciones educativas de la creatividad. Gowan, I.C. Demos, E. y Torrance, E.P. Salamanca: Anaya. iłusionarse por los procedimientos científicos necesarios para lograr sus propios objetivos.

En definitiva, el estudiante se transformo en sujeto del propio proceso de investigación, lo que contribuyó a que se ubicara desde una nueva perspectiva ente la resolución de problemas.

\section{AGRADECIMIENTOS}

Esta investigación forma parte de otra más amplia desarrollada con una subvención deI CIDE (Proyectos de Investigación Educativa, convocatoria de 1990).

Queremos dar las gracias a los profesores Ma. de los Ángeles Alonso María y Francisco Javier Boyano Sánchez, a los directivos de los centros y, muy especialmente, a los alumnos, por su colaboración.
HIERREZUELO, J. y MONTERO, A (1988). La ciencia de los alumnos. Barcelona: Laia-MEC.

KLAGES, F. (1968). Tratado de quimica orgánica. Tomo III. Campos especiales. Zaragoza: Reverté, S.A.

LLORENS MOLINA, J.A. (1991). Comenzando a aprender química. Ideas para el diseño curricular. Madrid: Visor.

OSBORNE, R.J. y FRYEBERG, P. (1991). El aprendizaje de las ciencias. Madrid: Narcea.

PORLAN, R, GARCÍA, J.E. y CAÑAL, P. (compiladores). (1995). Constructivismoyenseñanza de las ciencias. Sevilla: Díada.

POZO, J.I., GÓMEZ CRESPO, M.A., LIMÓN, M. Y SANZ SERRANO, A. (1991). Procesos cognitivos en la comprensión de la ciencia: Las ideas de los adolescentes sobre la química. Madrid: CIDE-MEC.

ROMOSANTOS, M. (1987). Treinta y cinco años de pensamiento divergente: Lacreatividad de Guilford. Estudios de psicologíu, 27-28, pp. 175-192.

VAN DE VRANDE, L. (1988). Teñido artesanal. BarceIona: CEAC.

WATSON, S.B. (1991). Coopcrative learning and group educational modules: effects on cognitive achievement of high school biology students. Journal of Research in Science Teaching, 28(2), pp. 141-146.

WHEATLEY,G.H. (1991). Constructivist perspective on science and mathematics learning. Science Education, 75(1), pp. 9-21. 


\section{ANEXO I}

A. Fichas informativas sobre la cochinilla y la cebolla. (Extraído del manual Teñido de la lana con productos colorantes naturales.)

\section{NOMBRE BOTÁNICO:}

Dactylopius coccus.

\section{COCHINILLA}

\section{DESCRIPCIÓN:}

Cochinilla es el nombre que se da a un colorante de origen animal. Los entomólogos agrupan en la familia Coccidae a un grupo de insectos que viven en un cacto y al que pertenece el insecto que nos ocupa.

\section{COMPOSICION:}

Et principio colorante de la cochinilla es el ácido carmínico.

\section{UTILIZACIÓN:}

Se utiliza como colorante. Según el mordiente empleado se obtienen distintos colores:

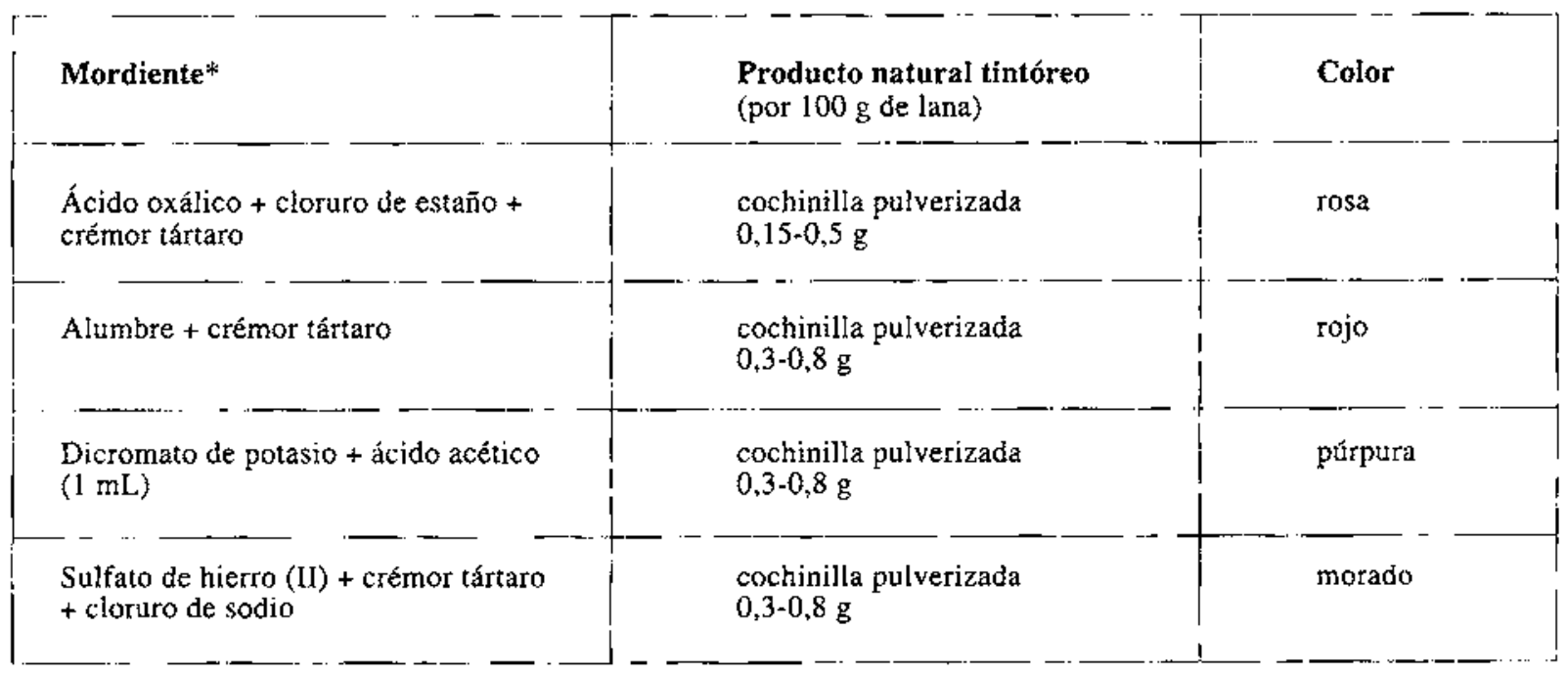

* Las disoluciones de los mordientes se deben preparar en el rango de concentraciones $10^{-1}-10^{-4} \mathrm{M}$. Se toman $50 \mathrm{~mL}$ de estas disoluciones por g de lana. 
NOMBRE BOTÁNICO:

\section{CFBOLIA}

Allium cepa $\mathrm{L}$.

\section{DESCRIPCION:}

La cebolla es una planta bianual vivaz y bulbosa. Su bulbo de considerable tamaño, redondeado o deprimido, está cubierto de binzas blancas.

\section{COMPOSICIÓN:}

Contiene colorantes flavonoides de Ios cuales el más importante es la quercetina.

\section{UTILIZACIÓN:}

Se utiliza como colorante. Según el mordiente utilizado se obtienen diversos colores:

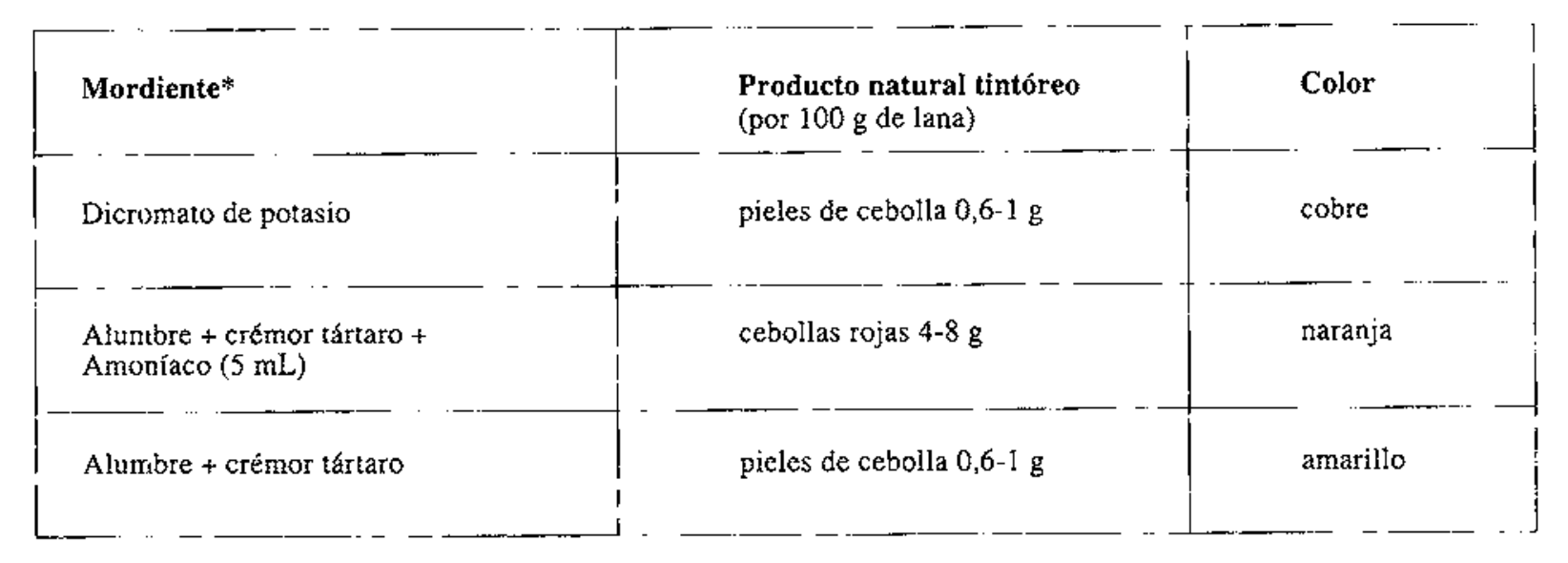

* Las disoluciones de los mordientes se deben preparar en el rango de concentraciones $10^{-1}-10^{-4} \mathrm{M}$. Se toman $50 \mathrm{~mL}$ de estas disoluciones por $\mathrm{g}$ de lana. 
B. Clasificación de las lanas españolas. (Extraído del manual Teñido de la lana con productos colorantes naturales.)

\section{- LANAS ESPAÑOLAS}

- Raza merina. Procedente de la Rioja, es tupida y algo amarillenta.

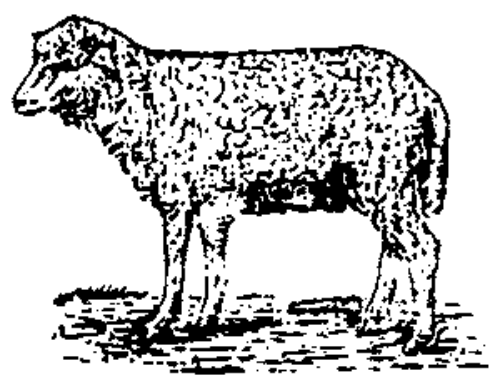

- Raza aragonesa. Procedente de Aragón, es fina, de color blanco-amarillento y bastante larga, es apropiada para la obtención de estambre.

- Raza manchega. Es blanca, de carácter estambrero.

- Raza ibérica o serrana. Es blanca, negra, castaña o gris, de briznas poco onduladas, gruesas, poco resistentes y flexibles.

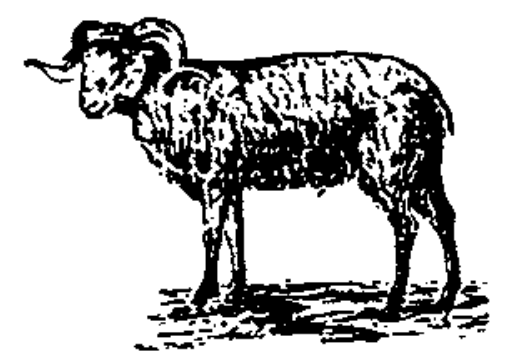

- Raza churra. Es blanca o gris oscura, de briznas largas. No es buena para tejidos, pero es excelente para colchones.

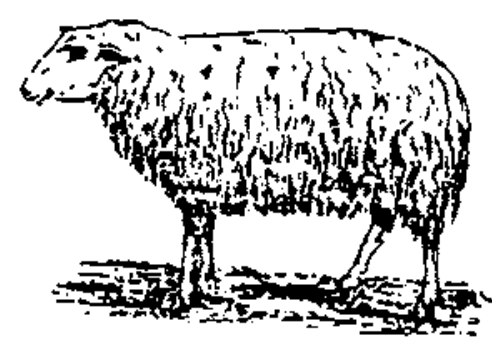




\section{ANEXO II}

Cuestionario sobre las ideas alternativas de los alumnos utilizado para la evaluación de contenidos conceptuales.

\section{EXPLORA TUS IDEAS}

1. Prueba para detectar el concepto de sustancia pura.

¿Cuál de los siguientes ejemplos corresponde a una sustancia pura? Justifica la respuesta.

a) Leche recién ordeñada.

b) Aire.

c) Cloruro de sodio.

2. Prucba para detectar el concepto de mezcla.

Observa una muestra de tierra. $¿$ Es una mezcla? Razona la respuesta.

3. Prutba para detectar el concepto de elemento.
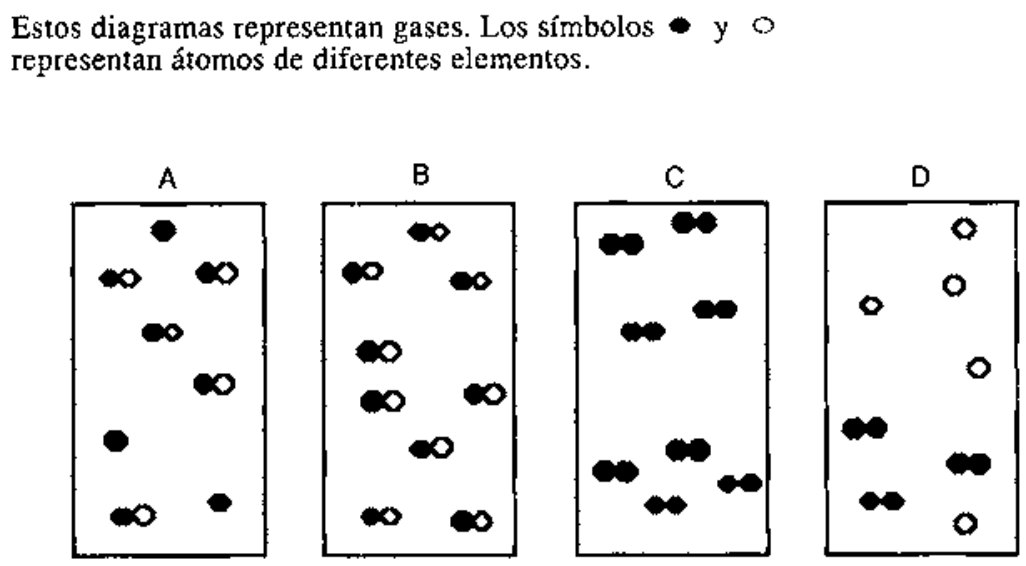
a) ¿Qué diagrama $A, B, C, D$ representa una mezcla de dos elementos?
b) ¿Cuál representa un compuesto?
c) ¿Cuál representa sólo un elemento?

4. Prueba para detectar el concepto de compuesto

Cuando se calientan $2 \mathrm{~g}$ de cinc y un gramo de azufre juntos, no queda prácticamente nada de cinc ni de azufre, una ve 2 que se ha formado el compuesto de sulfuro de cinc.

¿Qué ocurriría sì $2 \mathrm{~g}$ de cinc se calientan con $2 \mathrm{~g}$ de azuffe? Señala sólo una de las respuestas siguientes. Justifica la respuesta

a) El sulfuro de cinc contiene dos veces más de azufre que cuando se calientan $2 \mathrm{~g}$ de cinc y $1 \mathrm{~g}$ de azufre.

b) Se formará, como máximo, el doble de sulfuro de cinc.

c) Se formará la misma cantidad de sulfuro de cinc y quedará algo de azufre sin reaccionar.

d) Se formará la misma cantidad de sulfuro de cinc y quedará algo de cinc sin reaccionar. 
5. Prueba para detectar el concepto de disolución.

¿Cuál de los siguientes dibujos representa mejor las partículas de azúcar disueltas en agua? Justifica la respuesta.

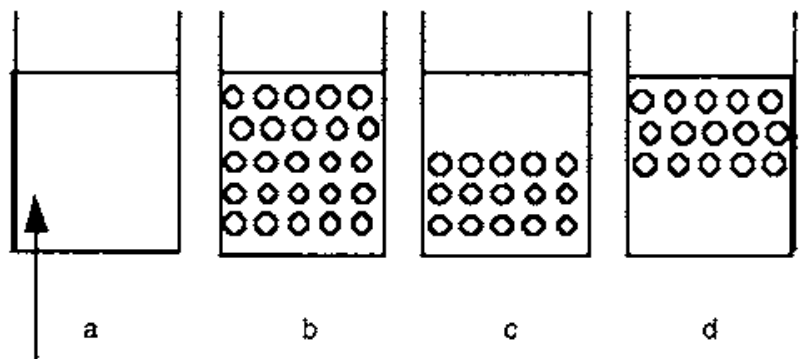

Ya no hay azúcar en el agua.

6. Prueba para detectar el concepto de disolución.

Los peces necesitan oxígeno para respirar. ¿De dónde lo obtienen?

- Del oxígeno disueito en el agua.

- Del oxigeno del agua $\left(\mathrm{H}_{2} \mathrm{O}\right)$, dejando el hidrógeno como residuo.

- De las burbujas de aire que hay en el agua.

7. Prueba para detectar el concepto de solubilidad.

En la limpieza en seco, en las tintorerías, utilizan distintos tipos de disolventes para eliminar los distintos tipos de manchas. ¿Qué acción producen estos disolventes?

8. Prueba para detectar métodos de separación de sustancias y el concepto de saturación.

La sal de cocina, como sabes, se obtiene del agua del mar. Esta agua se deja reposar en unas balsas de gran superficie y poca profundidad. El agua se evapora por la acción del sol y la sal queda en el fondo. ¿Qué propiedad característica utiliza este método de separación?

9. Prueba para detectar el concepto de saturación.

En el caso anterior, ¿será necesario evaporar totalmente el agua para obtener sal? Justifica la respuesta. 


\begin{abstract}
ANEXO HII
Cuestionarios finales para evaluar los contenidos conceptuales que tienen los alumnos.
\end{abstract}

\title{
CUESTIONARIO I
}

1) Justifica el diseño escogido.

2) ¿Por qué habéis establecido ese orden en el proceso?

3) ¿Cúál ha sido el orden seguido en la lectura de los materiales didácticos?

4) ¿Has echado de menos algún material adicional que tú consideres necesario para el diseño de la experiencia?

5) ¿Has utílizado algún libro o material didáctico adicional durante el desarrollo de la experiencia. Cita cuál y el grado de profundización que has obtenido.

6) ¿Por qué habéis empleado las concentraciones y los tiempos de ebullición recogidos?

\section{CUESTIONARIO II.A}

1) ¿Qué es un colorante? Identifica alguno.

2) ¿Cuál crees que es la diferencia entre materia colorante y pigmento?

3) Teniendo en cuenta lo que has aprendido en esta experiencia, propón un producto natural que pudiera ser empleado como sustancia colorante y trata de pensar en un diseño adecuado para obtener un color que sea de tu agrado.

4) ¿Qué es un mordiente? Identifica alguno.

5) ¿Qué definimos como grupo cromoforo? ¿Y como grupo auxocromo?

6) Identifica los grupos cromóforos y auxocromos del pigmento presente en el producto tintóreo elegido. 


\section{CUESTIONARIO II.B}

1) ¿Qué concepto teórico crees que te ha quedado más claro tras la experiencia? ¿Por quée?

2) Diferencias entre sistemas homogéneos y heterogéneos. Especifica ejemplos de ambos tipos, relacionados con tu experiencia.

3) Indica las distintas formas de expresar la concentración de las disoluciones llevadas a cabo en tu actividad.

4) ¿Cuál es la característica fundamental para identificar un ácido?

5) Identifica los grupos funcionales orgánicos del pigmento presente en el producto tintóreo elegido.

6) ¿A qué se debe la percepción de color? ¿Cuál o cuáles crees que son los factores determinantes a la hora de percibir un color determinado?

7) ¿A qué crees que se debe la aparición del color en determinadas sustancias?

CUESTIONARIO II. C

AGALLAS

ÁCIDO ELAGICO $\longrightarrow \quad$ ÁCIDO CHEBULICO

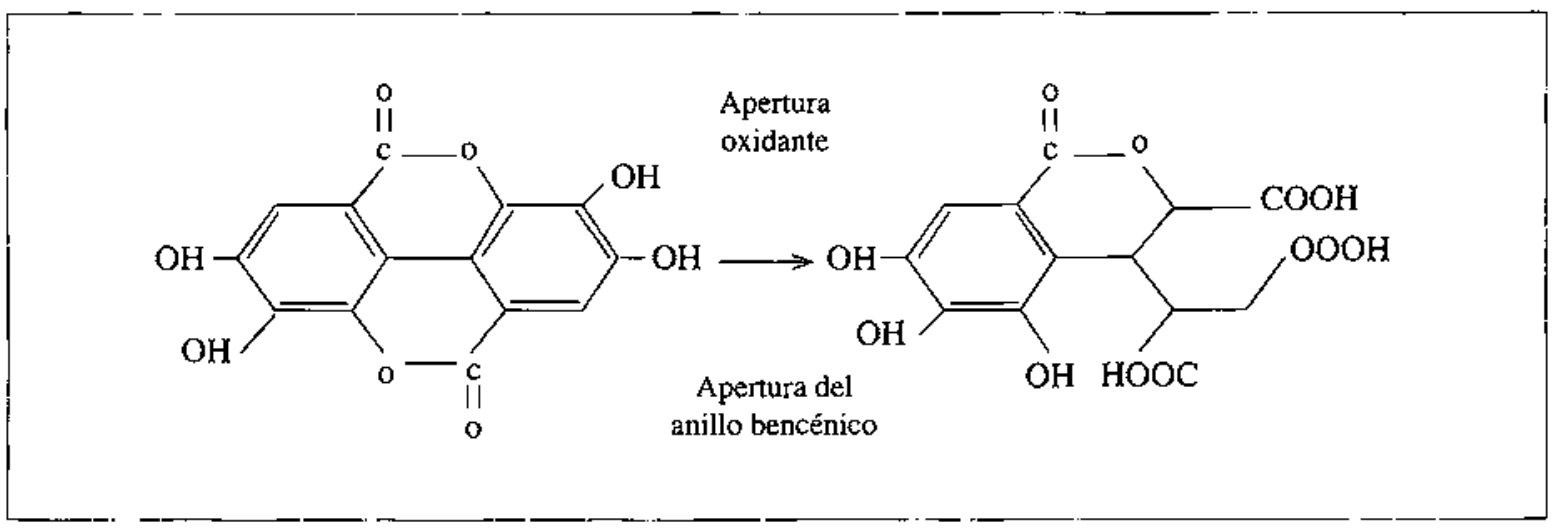

1) Escribe la fórmula molecular del pigmento.

2) ldentifica el grupo al que pertenece dicho pigmento.

3) Localiza e identifica los diferentes grupos funcionales presentes en la molécula de pigmento.

4) Analiza el carácter cromóforo y auxocrómico de los diferentes grupos. (Colorea de rojo los grupos cromóforos y de negro los auxocromos). 


\section{PRODUCTO NATURAL TINTÓREO: COCHINILLA}

2. MORDIENTE: CLORURO DE SODIO + CRÉMOR TÁRTARO

\subsection{ESQUEMA DE TEÑIDO:}

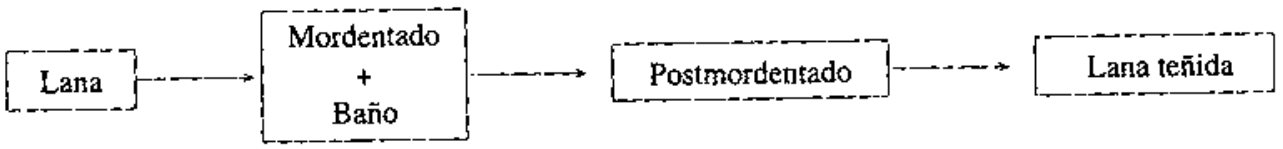

2.1.1. Mordiente

Baño

Disolución obtenida al hervir $0,6 \mathrm{~g}$ de cochinitla en $100 \mathrm{~mL}$ de agta.

$100 \mathrm{~mL}$ de disolución de $0,3 \mathrm{~g}$

Postmordiente de sulfato de hierro (II).

$100 \mathrm{~mL}$ de disolución de $0,4 \mathrm{~g}$ de sulfato de cobre (II).
Esta mezcla se hierve durante 2 minutos

Hervir durante $2 \mathrm{mns} \rightarrow$ gris verdoso oscuro

Hervir durante $5 \mathrm{mns} \rightarrow$ gris verdoso

\section{PRODUCTO NATURAL TINTÓREO: CÚRCUMA}

\section{MORDIENTE: ALUMBRE}

\subsection{ESQUEMA DE TEÑIDO:}

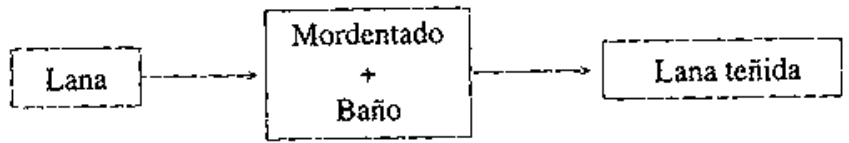

1.1.1. Mordiente

Baño
$50 \mathrm{~mL}$ de disolución obterida con $3 \mathrm{~g}$ de alumbre.

Disolución obtenida al hervir $6 \mathrm{~g}$ de cúrcuma en $100 \mathrm{~mL}$ de agua.
Esta mezcla se hierve dusante $\quad \rightarrow \quad$ amarillo vivo 20 minutos. 


\section{PRODUCTO NATURAL TINTÓREO: CEROLLA}

1. MORDIENTE: ÁCIDO OXÁLICO + ÁCIDO CLORHÍDRICO + DICROMATO DE POTASIO

\subsection{ESQUEMA DE TEÑIDO:}

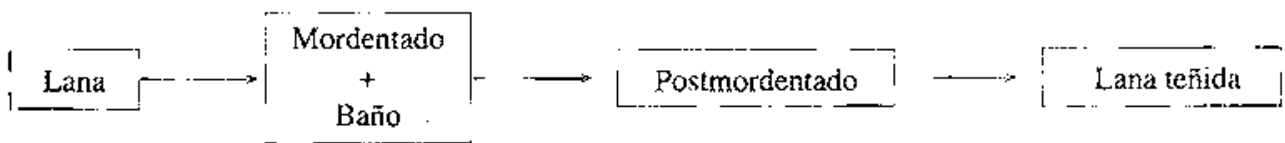

1.1.1. Mordiente

$100 \mathrm{~mL}$ de disolución obtenida con $2 \mathrm{~g}$ de ácido oxálico, $1 \mathrm{~mL}$ de ácido clorhídrico y $3 \mathrm{~g}$ de dicromato de potasio.

Baño Disolución obtenida al hervir $3 \mathrm{~g}$ de cebolla en $200 \mathrm{~mL}$ de agua.

$4 \mathrm{~g}$ de sulfato

Postmordiente $100 \mathrm{~mL}$ de agua.

Esta mezcla se hicrve durante 15 minutos

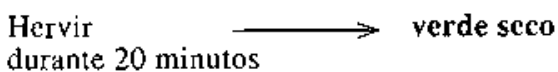
durante 20 minutos

\subsection{ESQUEMA DE TEÑIDO:}
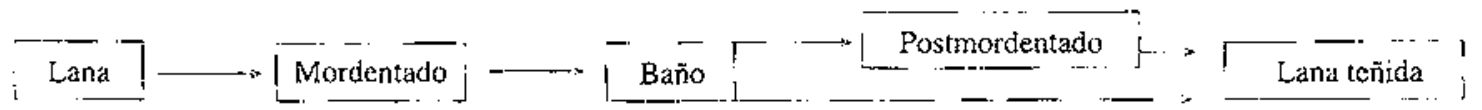

\begin{tabular}{l|l} 
2.2.I. Mordiente & \\
$100 \mathrm{~mL}$ de & \\
disolución & Hervir \\
obtenida & $2 \mathrm{mns}$ \\
con $2 \mathrm{~g}$ de & $\rightarrow$ \\
crémor tártaro, & $\rightarrow$ \\
$4 \mathrm{gde}$ dumbre & \\
y2 gde & \\
carbonato & \\
sódico. &
\end{tabular}

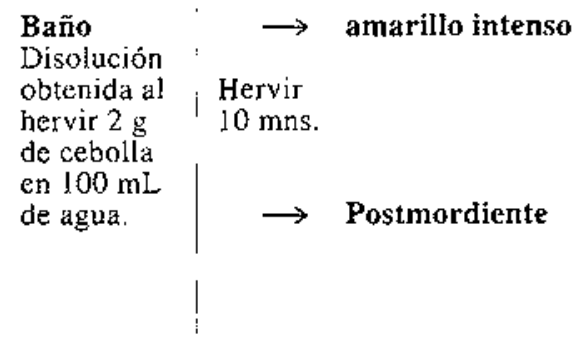

$$
\begin{array}{l|l}
4 \text { g de sulfato } \\
\text { de cobrc } \\
\text { (II) en } & \text { Hervir } \rightarrow \text { marrón } \\
100 \mathrm{~mL} & 10 \text { mns. } \\
\text { de agua. } & \text { claro }
\end{array}
$$




\section{ANEXO VI}

A. Plantilla para la evaluación de actitudes científicas.

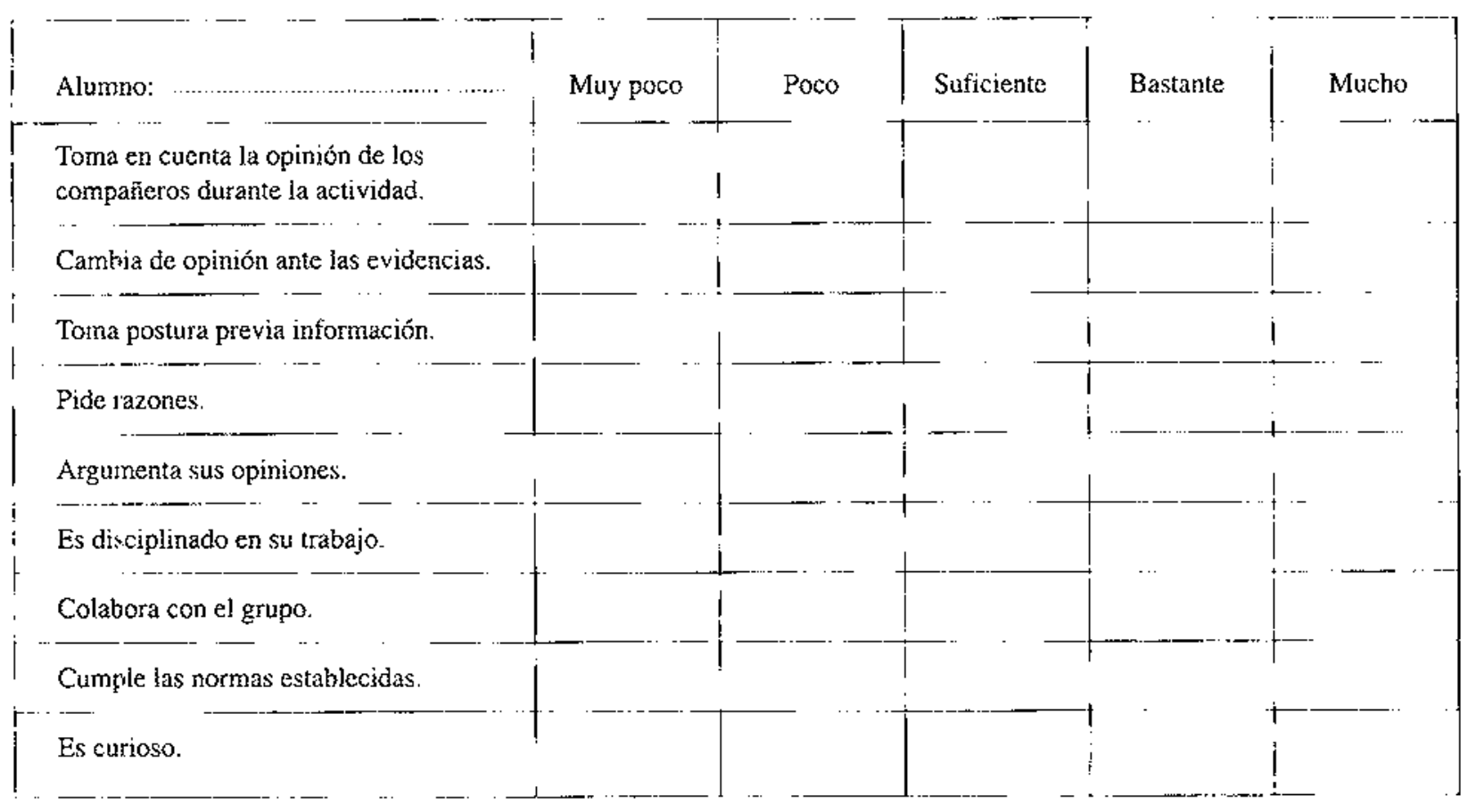

B. Evaluación de actitudes generales referidas al «problema investigativo» realizado.

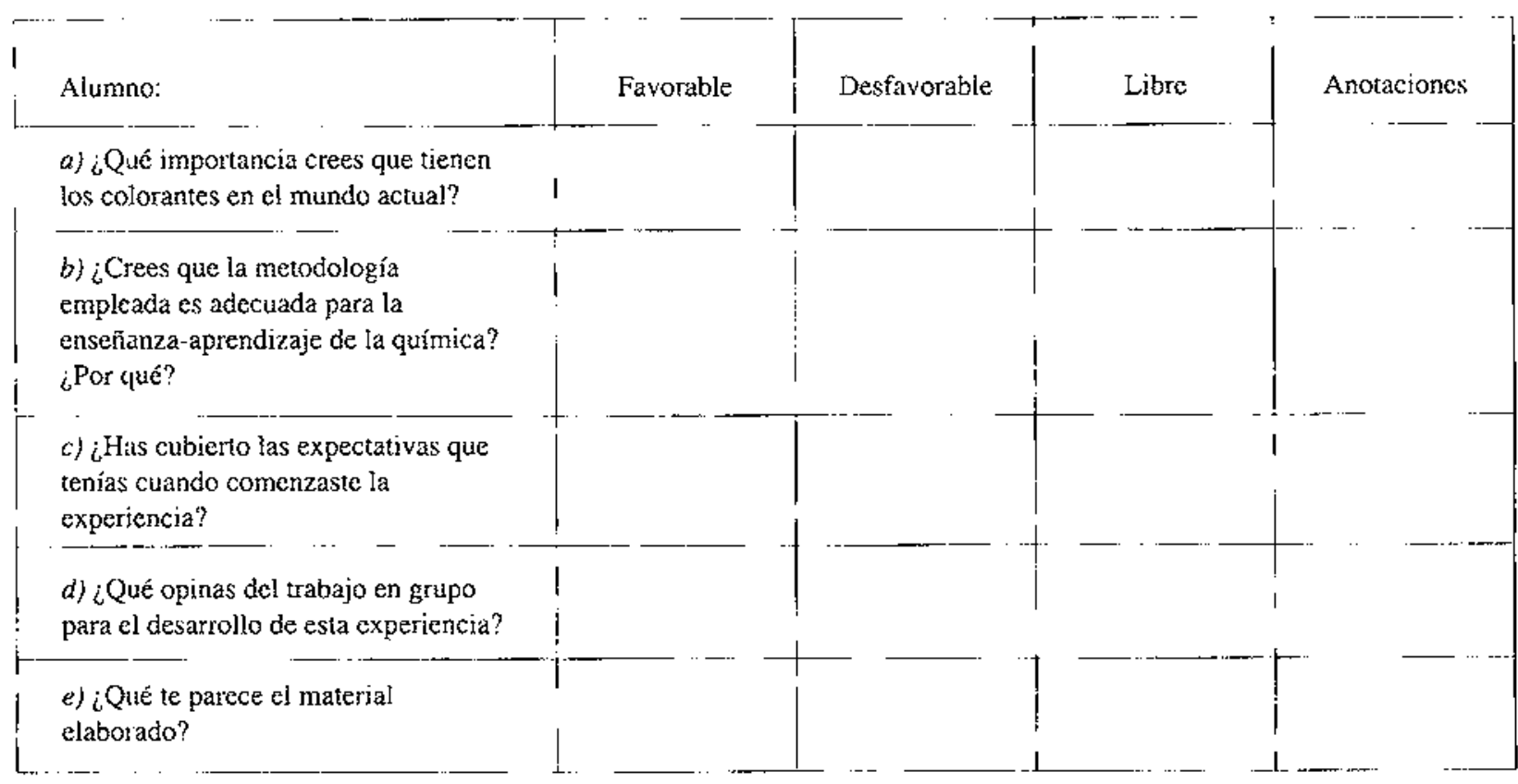

